\title{
Peran Orientasi Kewirausahaan dan Orientasi Pembelajaran untuk Meningkatkan Kinerja UMKM
}

\author{
Suyatmi ${ }^{1}$, Reza Widhar Pahlevi ${ }^{*}$ \\ ${ }^{1,2}$ Fakultas Ekonomi dan Sosial, Universitas Amikom Yogyakarta \\ 1mbak_ami@amikom.ac.id, ${ }^{2}$ rezawp@amikom.ac.id \\ *Penulis Korespondensi
}

\begin{abstract}
This study aims to determine the effect of entrepreneurial orientation and learning orientation on competitive advantage; determine the effect of entrepreneurial orientation and learning orientation on performance and determine the effect of competitive advantage on performance. The data collection method was obtained by using a questionnaire on MSME actors in the Special Region of Yogyakarta and collected 204 respondents. The data analysis tool uses the AMOS Structural Equation Modeling (SEM) technique. The results show that there is an influence between entrepreneurial orientations and learning orientation on competitive advantage, there is an influence between entrepreneurial orientation and competitive advantage on performance. However, there is no effect between learning orientation on performance.
\end{abstract}

Keywords: entrepreneurship orientation, learning orientation, competitive advantage, MSME performance

\begin{abstract}
Abstrak
Penelitian ini bertujuan untuk mengetahui pengaruh orientasi kewirausahaan dan orientasi pembelajaran terhadap keunggulan kompetitif; mengetahui pengaruh orientasi kewirausahaan dan orientasi pembelajaran terhadap kinerja dan mengetahui pengaruh keunggulan kompetitif terhadap kinerja. Metode pengumpulan data diperoleh dengan menggunakan kuesioner pada pelaku UMKM di Daerah Istimewa Yogyakarta dan terkumpul 204 responden. Alat analisis data menggunakan teknik Structural Equation Modelling (SEM) AMOS. Hasil penelitian menunjukkan adanya pengaruh antara orientasi kewirausahaan dan orientasi pembelajaran terhadap keunggulan kompetitif, terdapat pengaruh antara orientasi kewirausahaan dan keunggulan kompetitif terhadap kinerja. Namun tidak adanya pengaruh antara orientasi pembelajaran terhadap kinerja
\end{abstract}

Kata kunci: orientasi kewirausahaan, orientasi pembelajaran, keunggulan kompetitif, kinerja UMKM

Cara Mengutip:

Suyatmi., \& Pahlevi, R.W (2021). Peran Orientasi Kewirausahaan dan Orientasi Pembelajaran untuk Meningkatkan Kinerja UMKM. Esensi: Jurnal Bisnis dan Manajemen, 11(2), 157-168. https://doi.org/10.15408/ ess.v11i2.21826. 


\section{PENDAHULUAN}

Kinerja UMKM mengacu pada hasil dari aktivitas bisnis perusahaan. Keberhasilan UMKM atau kinerja UMKM diukur dengan menggunakan berbagai indikator. Salah satu pengukuran indikator menggunakan keunggulan kompetitif. Penerapan bisnis dengan orientasi kewirausahaan yang kuat akan berfokus untuk mencapai kinerja yang unggul dengan membangun strategi dengan penciptaan nilai bisnis yang tidak dapat ditiru oleh pesaing. Sehingga pelaku UMKM akan secara proaktif menghasilkan produk atau layanan baru yang inovatif, kreatif untuk mengungguli para pesaing (Hernández-Perlines, 2016; Martin \& Javalgi, 2016).

Orientasi pembelajaran dikonseptualisasikan sebagai sikap dasar terhadap pembelajaran, yaitu karakteristik organisasi dan manajerial yang memfasilitasi proses pembelajaran organisasi (Real dkk., 2014). Dalam konteks ini, orientasi belajar dipandang sebagai nilainilai perusahaan yang mempengaruhi kecenderungan perusahaan untuk menciptakan dan menggunakan pengetahuan (Mahmood \& Hanafi., 2013; Zhao dkk., 2011), dan komitmen manajemen untuk mendukung budaya yang menumbuhkan orientasi belajar sebagai salah satu aspek utamanya sebagai nilai-nilai (Real dkk., 2014).

Riset sebelumnya menunjukkan bahwa UMKM menghadapi banyak tantangan dan hambatan untuk bersaing di pasar global. Riset yang ditunjukkan oleh Saleh \& Ndubisi (2006) menjelaskan bahwa dalam lingkungan global, UMKM menghadapi berbagai tantangan karena kurangnya pembiayaan, produktivitas yang rendah, kurangnya kemampuan manajerial, dan minimnya akses manajemen dan teknologi. Selain itu, kontribusi UMKM terhadap total nilai tambah masih rendah karena keterbatasan dalam menggunakan teknologi, rendahnya kemampuan tenaga kerja, rendahnya peningkatan kapasitas produksi, dan minimnya perluasan pasar. Sementara itu, ingkat kegagalan UMKM sebagian besar disebabkan oleh lemahnya manajemen keuangan dan pemasaran (Mc Cartan-Quinn \& Carson, 2003; Salleh \& Ibrahim, 2013).

Permasalahan yang dihadapi UMKM karena skala ekonomi dan sumber daya mereka lebih sedikit daripada perusahaan besar. MacGregor (2004) menjelaskan bahwa karakteristik UMKM adalah unik dan sangat berbeda dari perusahaan besar, dalam hal organisasi memiliki struktur yang sederhana dan bersifat fleksibel dan cenderung informal. Selain itu, pemilik atau pengelola UMKM perlu terlibat penuh dalam operasional sehari-hari karena kurangnya keahlian manajemen para pengelola dibandingkan dengan perusahaan besar (Salleh \& Ibrahim, 2013). Terbatasnya sumber daya akan berdampak pada kinerja UMKM. Meskipun UMKM mungkin berbeda dari organisasi yang lebih besar dalam hal bagaimana mereka mengintegrasikan berbagai elemen, seperti pengetahuan, informasi, dan inovasi ke dalam orientasi kewirausahaan yang unik menjadi faktor kunci untuk bersaing. Oleh karena itu, UMKM perlu menekankan pada produktivitas, kualitas produk yang inovatif agar dapat bersaing dengan sukses dan mendapatkan keunggulan kompetitif di pasar global (Amin, 2015).

Kontribusi UMK mempunyai peran penting yang signifikan dalam menanggulangi masalah pengangguran. UMKM turut membantu penyerapan tenaga kerja pada negara maju ataupun negara berkembang seperti Indonesia. Menurut Mustikowati \& Tysari (2015) mengungkapkan bahwa fakta daya saing yang rendah UMKM menyebabkan mengalami kesulitan dalam meningkatkan kinerjanya. Studi saat ini secara bersamaan menyelidiki pengaruh orientasi kewirausahaan pada kinerja UMKM di bawah mediasi keunggulan kompetitif (Shepherd \& 
Wiklund, 2009). Potensi yang dimiliki oleh UMKM belum mampu mengimbangi kemampuan UMKM untuk bersaing. Daya saing yang rendah mengakibatkan posisi perusahaan tergeser hingga tidak aman dalam persaingan bisnis.

Penelitian yang dilakukan Hernández-Perlines (2016) menjelaskan bahwa bisnis dengan orientasi kewirausahaan yang baik akan berfokus pada peningkatan kinerja yang unggul dengan membangun strategi dan penciptaan nilai tambah yang tidak dapat ditiru oleh pesaing lain. Riset Ribeiro dkk. (2021) dan Wang dkk. (2020) menunjukkan hasil bahwa orientasi kewirausahaan umumnya berkontribusi pada kemampuan perusahaan untuk menumbuhkan jaringan internal dan eksternal (akuisisi sumber daya dan ikatan bisnis) dan juga memaksimalkan kinerja. Orientasi wirausaha dapat memberikan jaminan kepada perusahaan perusahaan jangka panjang dan keunggulan kompetitif berkelanjutan (D’Angeloa \& Manuela, 2019).

Hasil berbeda ditemukan pada hasil riset Salleh \& Ibrahim (2013) yang menunjukkan bahwa peningkatan kinerja tidak hanya berasal dari orientasi wirausaha tetapi terbatasnya sumber daya akan berdampak pada kinerja UMKM. Meskipun UMKM mungkin berbeda dari organisasi yang lebih besar dalam hal bagaimana mereka mengintegrasikan berbagai elemen, seperti pengetahuan, informasi, dan inovasi. Orientasi kewirausahaan tidak terkait dengan variabel level individu seperti pada teori kewirausahaan sebelumnya, ini terkait dengan proses level perusahaan (Linares et al, 2018). Terutama perusahaan yang baru didirikan harus sangat berhati-hati dalam mengejar orientasi karena mereka memiliki sumber daya keuangan dan manajerial yang terbatas (Soares et al, 2020). Hasil yang tidak konsisten dari penelitian terdahulu merupakan gap riset dan menjadi celah bagi peneliti untuk meneliti lebih lanjut mengenai peran orientasi kewirausahaan dan orientasi pembelajaran terhadap keunggulan kompetitif dan kinerja UMKM.

\section{METODE}

Pendekatan penelitian ini menggunakan metode survei dengan desain cross-sectional yang digunakan untuk mengumpulkan data dari pengelola atau pemilik UMKM di Daerah Istimewa Yogyakarta. Ukuran sampel untuk penelitian ditentukan dengan "rule of thumb" di bawah panduan persyaratan untuk teknik analisis data (Hair dkk, 2013). Pemodelan persamaan struktural membutuhkan 15-20 observasi untuk setiap variabel independen atau prediktor (Hair dkk, 2013). Penelitian ini menggunakan konstruk orientasi kewirausahaan dan orientasi pembelajaran sebagai prediktor kinerja dan keunggulan kompetitif UMKM. Selanjutnya, konstruk keunggulan kompetitif digunakan sebagai prediktor kinerja UMKM.

Definisi operasional variabel orientasi kewirausahaan adalah orientasi strategis bisnis mengenai praktik, proses, dan aktivitas yang menjadi dasar inovasi dan pengambilan keputusan untuk memasuki pasar (Ciampi dkk, 2020), pada variabel ini menggunakan indikator innovativeness, pro-activeness, risk taking, competitive aggressiveness dan autonomy (Campos dkk, 2012; Kiyabo \& Isaga, 2020). Orientasi pembelajaran merupakan nilai-nilai perusahaan yang mempengaruhi kecenderungan perusahaan untuk menciptakan dan menggunakan pengetahuan, serta adanya komitmen manajemen untuk mendukung budaya yang menumbuhkan orientasi belajar sebagai salah satu aspek utama dalam nilai-nilai bisnis (Wang, 2008; Zhao dkk., 2011), pada variabel ini menggunakan indikator Commitment to 
learning, Shared vision, Open-mindedness (Amin, 2015; Wang, 2008). Keunggulan kompetitif adalah kemampuan suatu perusahaan dalam menghasilkan produk yang tidak dimiliki dan tidak dapat ditiru pesaing dengan memandang seluruh proses perusahaan mulai dari mendesain, memproduksi, memasarkan hingga menyerahkan produk jadi tersebut kepada konsumen (termasuk didalamnya strategi untuk mendukung penjualan) (Kiyabo \& Isaga, 2020), pada variabel ini menggunakan indikator Differentiated product, Market sensing dan Market responsiveness (Ramaswami dkk, 2006; Kiyabo \& Isaga, 2020), pada variabel ini menggunakan indikator Return on capital employed, Sales growth dan Earnings per share (Shepherd \& Wiklund, 2009; Wang, 2008).

Teknik pemodelan persamaan struktural menggunakan statistik chi-square untuk menilai kesesuaian model. Statistik chi-square terhadap ukuran sampel yang tinggi, yaitu semakin besar ukuran sampel, semakin tinggi kemungkinan model akan gagal (Barret, 2007). Dengan demikian, ukuran sampel 100 hingga 400 subjek disarankan untuk model yang memerlukan penggunaan pemodelan persamaan struktural (Hair dkk., 2013). Dengan menggunakan rule of thumb, ukuran sampel sebanyak 200 subjek dianggap memadai untuk itu digunakan dalam penelitian ini. Peneliti memperoleh kuesioner lengkap sebanyak 204 responden. Teknik analisis data yang digunakan dalam penelitian ini adalah metode Structral Equation Model (SEM) dengan menggunakan software AMOS.

Gambar 1. Model Analisis

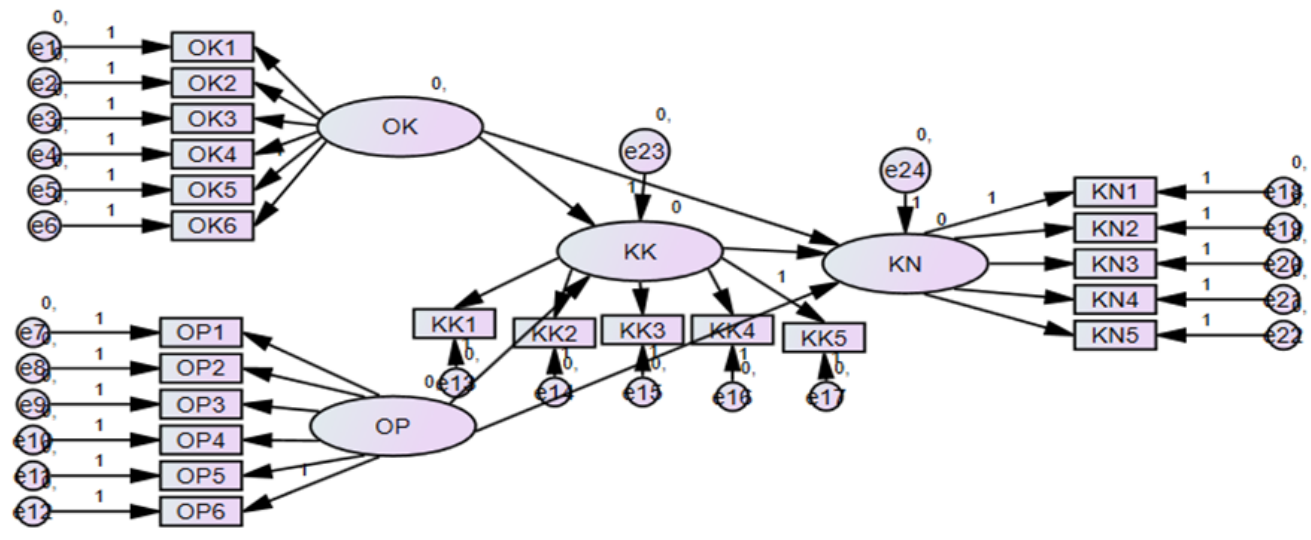

Sumber: Data Diolah, 2021

\section{HASIL DAN PEMBAHASAN}

\section{Hasil Empiris}

Data yang digunakan merupakan data primer hasil kuesioner yang disebarkan kepada responden penelitian yaitu sejumlah 204 pengelola atau pemilik UMKM di Daerah Istimewa Yogyakarta. Berikut hasil uji validitas berdasarkan perhitungan dapat dilihat pada Tabel 1. Berdasarkan Tabel 1, nilai yang dihitung dari semua item kuesioner termasuk variabel penelitian yaitu orientasi kewirausahaan, orientasi pembelajaran, keunggulan kompetitif dan kinerja menunjukkan nilai probabilitas (sig) $<0,05$. Jadi kuesioner dari variabel penelitian semuanya valid, dan nilai Cronbach Alpha diperoleh dari semua hasil termasuk variabel penelitian yaitu orientasi kewirausahaan, orientasi pembelajaran, keunggulan kompetitif dan kinerja yang menunjukkan lebih besar dari nilai 0,6 dan itu berarti dapat dihandalkan. 
Tabel 1. Hasil Uji Validitas dan Reliabilitas

\begin{tabular}{|c|c|c|c|c|c|}
\hline Variabel & $\begin{array}{c}\text { Item } \\
\text { Pertanyaan }\end{array}$ & $\begin{array}{c}\text { Pearson } \\
\text { Correlation }\end{array}$ & Signifikansi & Keputusan & Cronbach'sAlpha \\
\hline \multirow{6}{*}{$\begin{array}{c}\text { Orientasi } \\
\text { Kewirausahaan }\end{array}$} & Item 1 & 0,583 & 0,000 & Valid & 0,754 \\
\hline & Item 2 & 0,774 & 0,000 & Valid & \\
\hline & Item 3 & 0,613 & 0,000 & Valid & \\
\hline & Item 4 & 0,618 & 0,000 & Valid & \\
\hline & Item 5 & 0,600 & 0,000 & Valid & \\
\hline & Item 6 & 0,824 & 0,000 & Valid & \\
\hline \multirow{6}{*}{$\begin{array}{c}\text { Orientasi } \\
\text { Pembelajaran }\end{array}$} & Item 1 & 0,832 & 0,000 & Valid & 0,800 \\
\hline & Item 2 & 0,747 & 0,000 & Valid & \\
\hline & Item 3 & 0,694 & 0,000 & Valid & \\
\hline & Item 4 & 0,682 & 0,000 & Valid & \\
\hline & Item 5 & 0,681 & 0,000 & Valid & \\
\hline & Item 6 & 0,672 & 0,000 & Valid & \\
\hline \multirow{5}{*}{$\begin{array}{l}\text { Keunggulan } \\
\text { Kompetitif }\end{array}$} & Item 1 & 0,806 & 0,000 & Valid & 0,829 \\
\hline & Item 2 & 0,840 & 0,000 & Valid & \\
\hline & Item 3 & 0,815 & 0,000 & Valid & \\
\hline & Item 4 & 0,869 & 0,000 & Valid & \\
\hline & Item 5 & 0,539 & 0,000 & Valid & \\
\hline \multirow[t]{5}{*}{ Kinerja } & Item 1 & 0,819 & 0,000 & Valid & 0,785 \\
\hline & Item 2 & 0,597 & 0,000 & Valid & \\
\hline & Item 3 & 0,729 & 0,000 & Valid & \\
\hline & Item 4 & 0,668 & 0,000 & Valid & \\
\hline & Item 5 & 0,872 & 0,000 & Valid & \\
\hline
\end{tabular}

*Signifikan pada level $5 \%$

Sumber: Data Diolah, 2021

Kemudian sebelum menjawab hipotesis penelitian, pada bagian hasil penelitian akan menjelaskan mengenai deskriptif responden yaitu untuk mengetahui gambaran atau tanggapan responden terhadap variabel penelitian. Tabel 2 menunjukkan nilai rata-rata mengenai tanggapan responden.

Tabel 2. Statistik Deskriptif

\begin{tabular}{clcc}
\hline No & \multicolumn{1}{c}{ Variabel } & Rerata & Kategori \\
\hline 1 & Orientasi Kewirausahaan & 3,96 & Baik \\
2 & Orientasi Pembelajaran & 4,40 & Sangat Baik \\
3 & Keunggulan Kompetitif & 4,19 & Baik \\
4 & Kinerja & 4,33 & Sangat Baik \\
\hline
\end{tabular}

Sumber: Data Diolah, 2021 
Tabel 2 menunjukkan bahwa variabel orientasi kewirausahaan dan keunggulan kompetitif memiliki skor di kisaran 3,41 sd 4,20. Sedangkan orientasi pembelajaran dan kinerja memiliki skor di kisaran 4,21 sd 5,00 sudah sangat baik dipersepsikan responden. Hal ini menunjukkan sudah baik pemahaman orientasi kewirausahaan dan keunggulan kompetitif responden. Sedangkan orientasi pembelajaran dan kinerja kategori sudah sangat baik dirasakan oleh responden.

Selanjutnya hasil Structural Equation Model (SEM) pada persamaan struktural terlihat pada Gambar 2. Gambar 2 menerangkan bahwa indikator-indikator masing-masing variabel mampu merefleksikan variabel penelitian. Model struktural tersebut menggambarkan pengaruh orientasi kewirausahaan dan orientasi pembelajaran terhadap keunggulan kompetitif dan kinerja.

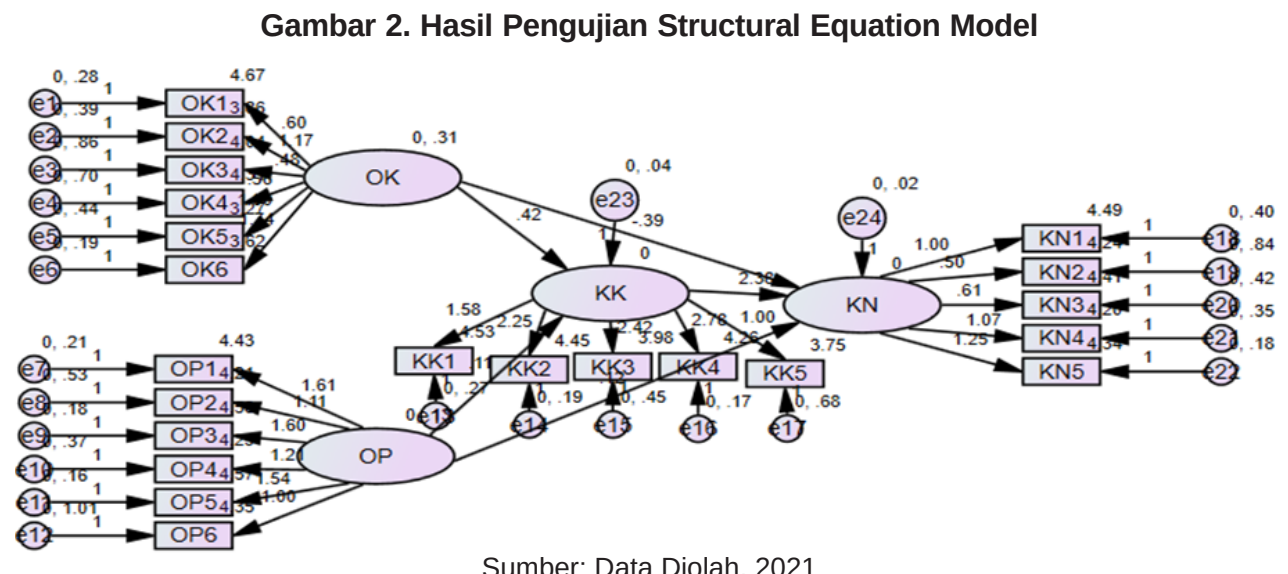

Sumber: Data Diolah, 2021

Nilai pengaruh orientasi kewirausahaan terhadap keunggulan kompetitif sebesar 0,751; nilai pengaruh orientasi pembelajaran terhadap keunggulan kompetitif sebesar 0,125 ; nilai pengaruh orientasi kewirausahaan terhadap kinerja sebesar -0,351; nilai pengaruh orientasi pembelajaran terhadap kinerja sebesar 0,067 serta nilai pengaruh keunggulan kompetitif terhadap kinerja sebesar 1,200. Selanjutnya pengujian model dalam Structural Equation Model dilakukan dengan dua pengujian, yaitu uji kesesuaian model dan uji signifikansi kausalitas melalui uji koefisien regresi.

Tabel 3. Hasil Pengujian Kelayakan Model

\begin{tabular}{cccc}
\hline Kriteria & Cut ofValue & Hasil & Keterangan \\
\hline Chi-Square & 37,65 & 443,499 & Fit \\
Probability & $\geq 0,05$ & 0,059 & Fit \\
CMIN/DF & $\leq 2,00$ & 1,223 & Fit \\
GFI & $\geq 0,90$ & 0,924 & Fit \\
AGFI & $\geq 0,90$ & 0,946 & Fit \\
TLI & $\geq 0,95$ & 0,966 & Fit \\
CFI & $\geq 0,95$ & 0,987 & Fit \\
RMSEA & $\leq 0,08$ & 0,062 & Fit \\
\hline
\end{tabular}

Sumber: Data Diolah, 2021

Hasil dari pengujian kelayakan model penelitian menunjukkan bahwa semua kriteria goodnessof fit dapat diterima. Dengan demikian, model akhir yang dikembangkan adalah sesuai (fit) dengan data. 
Tabel 4. Hasil Pengujian Hipotesis

\begin{tabular}{|c|c|c|c|c|c|}
\hline & & $\begin{array}{l}\text { Standardized } \\
\text { direct effect }\end{array}$ & C.R. & $p$-value & Hasil Uji \\
\hline \multicolumn{6}{|c|}{ Persamaan ke-1: $Z Y_{1}=Y_{1.1} X_{1}+Y_{1.2} X_{2}+\varepsilon_{1}$} \\
\hline Orientasi Kewirausahaan & Keunggulan Kompetitif & 0,751 & 4,504 & $0,000^{*}$ & Signifkan \\
\hline Orientasi Pembelajaran & Keunggulan Kompetitif & 0,125 & 1,837 & $0,066^{\star *}$ & Signifikan \\
\hline \multicolumn{6}{|c|}{ Persamaan ke-2: $Z Y_{2}=Y_{2.1} Y_{1}+Y_{2.2} X_{1}+Y_{2.3} X_{2}+\varepsilon_{2}$} \\
\hline Orientasi Kewirausahaan & Kinerja & $-0,351$ & $-3,695$ & $0,000^{*}$ & Signifkan \\
\hline Orientasi Pembelajaran & Kinerja & 0,067 & 1,335 & $0,182^{*}$ & $\begin{array}{c}\text { Tidak } \\
\text { Signifikan }\end{array}$ \\
\hline Keunggulan Kompetitif & Kinerja & 1,200 & 4,662 & $0,000^{*}$ & Signifikan \\
\hline
\end{tabular}

*Signifikan pada level $5 \%$

**Signifikan pada level $10 \%$

Sumber: Data Diolah, 2021

Pengaruh total, pengaruh langsung dan pengaruh tidak langsung antara variabel orientasi kewirausahaan $\left(\mathrm{X}_{1}\right)$, orientasi pembelajaran $\left(\mathrm{X}_{2}\right)$ keunggulan kompetitif $\left(\mathrm{Y}_{1}\right)$ dan kinerja $\left(\mathrm{Y}_{2}\right)$ dapat disajikan dalam model pada Tabel 5.

Tabel 5. Pengaruh Total, Pengaruh Langsung Dan Pengaruh Tidak Langsung Antara Variabel Eksogen Dan Endogen

\begin{tabular}{lcccc}
\hline \multirow{2}{*}{ Variabel } & \multicolumn{2}{c}{ Pengaruh Langsung } & $\begin{array}{c}\text { Pengaruh Tidak } \\
\text { Langsung }\end{array}$ & $\begin{array}{c}\text { Pengaruh } \\
\text { Total }\end{array}$ \\
\cline { 2 - 5 } & $\begin{array}{c}\text { keunggulan } \\
\text { kompetitif }\left(\mathrm{Y}_{1}\right)\end{array}$ & kinerja $\left(\mathrm{Y}_{2}\right)$ & kinerja $\left(\mathrm{Y}_{2}\right)$ & kinerja $\left(\mathrm{Y}_{2}\right)$ \\
\hline orientasi kewirausahaan $\left(\mathrm{X}_{1}\right)$ & 0,751 & $-0,351$ & 0,901 & 0,550 \\
orientasi pembelajaran $\left(\mathrm{X}_{2}\right)$ & 0,125 & 0,067 & 0,150 & 0,218 \\
keunggulan kompetitif $\left(\mathrm{Y}_{1}\right)$ & - & 1,200 & - & 1,200 \\
\hline
\end{tabular}

Sumber: Data Diolah, 2021

\section{PEMBAHASAN}

Hasil penelitian menunjukkan bahwa terdapat pengaruh antara orientasi kewirausahaan terhadap keunggulan kompetitif dengan nilai arah koefisien sebesar 0,751 dan signifikan dengan nilai probabilitas 0.000. Hasil penelitian ini sejalan dengan temuan Ribeiro dkk. (2021), Wang dkk. (2020) bahwa orientasi kewirausahaan umumnya berkontribusi pada kemampuan perusahaan untuk menumbuhkan jaringan internal dan eksternal (akuisisi sumber daya dan ikatan bisnis) dan juga memaksimalkan keunggulan kompetitif berkelanjutan. Orientasi wirausaha dapat memberikan jaminan kepada perusahaan perusahaan jangka panjang dan keunggulan kompetitif berkelanjutan (D’Angeloa \& Manuela, 2019). Temuan ini sesuai dengan teori berbasis sumber daya yang menunjukkan bahwa keunggulan kompetitif perusahaan dan kinerja yang unggul berasal dari sumber daya dan kapabilitas spesifik perusahaan (Barney, 1991). Terlepas dari pentingnya keunggulan kompetitif dalam mempromosikan kinerja perusahaan seperti yang disarankan dalam pandangan berbasis sumber daya, penelitian 
sebelumnya tidak memberikan banyak perhatian dalam mempelajari efek mediasinya pada hubungan orientasi kewirausahaan-kinerja perusahaan (Mahmood \& Hanafi, 2013). Namun, beberapa penelitian telah mengamati pengaruh positif dan signifikan orientasi kewirausahaan terhadap keunggulan bersaing (Mustafa \& Menon, 2015).

Hasil penelitian menunjukkan bahwa terdapat pengaruh antara orientasi pembelajaran terhadap keunggulan kompetitif dengan nilai arah koefisien sebesar 0,125 dan signifikan dengan nilai probabilitas 0.066 . Orientasi pembelajaran telah menarik minat para akademisi selama beberapa dekade (Brettel \& Rottenberger, 2013; Hakala, 2011). Orientasi belajar dikonseptualisasikan sebagai sikap dasar terhadap pembelajaran mengenai karakteristik organisasi dan manajerial yang memfasilitasi proses pembelajaran organisasi (Real dkk., 2012). Penelitian sebelumnya telah menemukan bahwa orientasi pembelajaran memiliki pengaruh yang signifikan terhadap kinerja UMKM (Real dkk., 2012; Wang, 2008). Misalnya, Brettel \& Rottenberger (2013) menganggap bahwa pembelajaran merupakan komponen utama dari setiap upaya untuk meningkatkan keunggulan kompetitif dan kinerja organisasi. Selain itu, Rhee dkk. (2010) melakukan penelitian terhadap kinerja UMKM, yang mengimplikasikan bahwa manajer dengan orientasi kewirausahaan dan orientasi pasar harus lebih menekankan pada orientasi pembelajaran untuk mendorong inovasi, dan pada akhirnya mencapai kinerja yang lebih baik. Dalam hal ini, UMKM dengan tingkat orientasi pembelajaran yang tinggi dikaitkan dengan inovasi yang lebih besar dan umumnya mengungguli pesaing mereka dengan kinerja yang unggul.

Hasil penelitian menunjukkan bahwa terdapat pengaruh antara orientasi kewirausahaan terhadap kinerja dengan nilai arah koefisien sebesar -0,351 dan signifikan dengan nilai probabilitas 0.000 . Bisnis dengan orientasi kewirausahaan yang kuat akan berfokus untuk mendapatkan kinerja yang unggul dengan membangun strategi dengan penciptaan nilai yang tidak dapat ditiru oleh pesaing lain, atau merasa terlalu mahal untuk ditiru. Oleh karena itu, kewirausahaan mewakili orientasi strategis organisasi dengan mengabaikan keuntungan dalam jangka pendek dan berinvestasi dalam peluang berisiko lebih tinggi untuk manfaat jangka panjang dan penciptaan nilai. Akibatnya, perusahaan tersebut secara proaktif menghasilkan produk atau layanan baru dan inovatif, secara kreatif mengungguli pesaingnya (Hernández-Perlines, 2016; Martin \& Javalgi, 2016). Rhee dkk. (2010) melakukan penelitian terhadap kinerja UMKM, yang mengimplikasikan bahwa manajer dengan orientasi kewirausahaan dan orientasi pasar harus lebih menekankan pada orientasi pembelajaran untuk mendorong inovasi, dan pada akhirnya mencapai kinerja yang lebih baik. Dalam hal ini, UMKM dengan tingkat orientasi pembelajaran yang tinggi dikaitkan dengan inovasi yang lebih besar dan umumnya mengungguli pesaing mereka dengan kinerja yang unggul (Brettel \& Rottenberger, 2013).

Hasil penelitian menunjukkan bahwa tidak terdapat pengaruh antara orientasi pembelajaran terhadap kinerja dengan nilai arah koefisien sebesar 0,067 dan signifikan dengan nilai probabilitas 0.182. Sejalan dengan hasil penelitian Salleh \& Ibrahim (2013) yang menunjukkan bahwa peningkatan kinerja tidak hanya berasal dari orientasi wirausaha dan pembelajaran tetapi terbatasnya sumber daya akan berdampak pada kinerja UMKM. Meskipun UMKM mungkin berbeda dari organisasi yang lebih besar dalam hal bagaimana mereka mengintegrasikan berbagai elemen, seperti pengetahuan, informasi, dan inovasi. Orientasi 
pembelajaran tidak terkait dengan variabel level individu seperti pada teori kewirausahaan sebelumnya, ini terkait dengan proses level perusahaan (Linares dkk., 2018). Terutama perusahaan yang baru didirikan harus sangat berhati-hati dalam mengejar orientasi karena mereka memiliki sumber daya keuangan dan manajerial yang terbatas (Soares dkk., 2020).

Hasil penelitian menunjukkan bahwa terdapat pengaruh antara keunggulan kompetitif terhadap kinerja dengan nilai arah koefisien sebesar 1,200 dan signifikan dengan nilai probabilitas 0.000. Menurut teori berbasis sumber daya perusahaan, keunggulan kompetitif hanya muncul dari penggunaan aset yang langka, tidak berwujud dan spesifik perusahaan. Basis sumber daya internal perusahaan merupakan faktor penentu keunggulan bersaing pada perusahaan kecil dan menengah. Literatur selanjutnya menegaskan bahwa keunggulan kompetitif dan kinerja perusahaan sebagian besar dipengaruhi oleh perilaku kewirausahaan perusahaan (Wiklund \& Shepherd, 2005). Namun, masih ada penelitian empiris terbatas yang menyelidiki efek mediasi dari keunggulan bersaing pada hubungan orientasi kewirausahaankinerja bisnis. Penelitian Wiklund (1999) menegaskan bahwa terdapat hubungan positif antara orientasi kewirausahaan dan kinerja. Penelitian sebelumnya melaporkan hubungan positif dan signifikan antara orientasi kewirausahaan dan kinerja perusahaan. Mahmood \& Hanafi (2013) menemukan bahwa orientasi kewirausahaan adalah prediktor yang berharga untuk bisnis. Oleh karena itu, penelitian orientasi kewirausahaan mengumpulkan banyak bukti mengenai hubungan antara orientasi kewirausahaan dan hasil atau kinerja (Wiklund, 1999; Wiklund \& Shepherd, 2005). Orientasi kewirausahaan juga merupakan sumber daya dan kapabilitas yang menghadirkan keunggulan kompetitif yang langgeng dan kinerja yang unggul bagi perusahaan.

\section{SIMPULAN}

Hasil penelitian menunjukkan adanya pengaruh antara orientasi kewirausahaan dan orientasi pembelajaran terhadap keunggulan kompetitif, terdapat pengaruh antara orientasi kewirausahaan dan dan keunggulan kompetitif terhadap kinerja. Namun tidak adanya pengaruh antara orientasi pembelajaran terhadap kinerja. Meskipun UMKM mungkin berbeda dari organisasi yang lebih besar dalam hal bagaimana mereka mengintegrasikan berbagai elemen, seperti pengetahuan, informasi, dan inovasi ke dalam orientasi kewirausahaan yang unik menjadi faktor kunci untuk bersaing. Oleh karena itu, UMKM perlu menekankan pada produktivitas, kualitas produk yang inovatif agar dapat bersaing dengan sukses dan mendapatkan keunggulan kompetitif di pasar global.

Bagi pelaku UMKM perlu memperhatikan peran orientasi kewirausahaan dalam meningkatkan kinerja. Sehingga dapat menghadapi dan memenangkan persaingan di pasar. Pelaku UMKM diharapakan memanfaatkan sebagai masukan tentang peran orientasi kewirausahaan dan pembelajaran dalam meningkatkan kinerja perusahaan. Sehingga dapat menghadapi dan memenangkan persaingan di pasar. Berdasarkan kesimpulan dan keterbatasan tersebut untuk memperoleh hasil penelitian yang lebih baik pada penelitian yang akan datang, maka saran yang perlu diperhatikan diantaranya yaitu mengklasifikasikan skala usaha UMKM menjadi UMKM yang berskala kecil dan berskala besar serta mengklasifikasikan berdasarkan jenis usaha UMKM. Dengan begitu diharapkan hasil penelitian dapat dibandingkan bagaimana pengaruhnya berdasarkan skala usaha, serta dapat mengamati pada fokus UMKM E-Commerce. 


\section{PUSTAKA ACUAN}

Amin, M. (2015). The Effect of Entrepreneurship Orientation and Learning Orientation on SMEs' Performance: an SEM-PLS Approach. Journal for International Business and Entrepreneurship Development, 8(3), 215-220. https://doi.org/10.1504/jibed.2015.070797.

Barret, P. (2007). Structural Equation Modelling: Adjudging Model Fit. Personality And Individual Differences, 42(5), 815-824. https://doi.org/10.1016/j.paid.2006.09.018.

Barney . (1991). Firm Resources and Sustained Competitive Advantage. Journal of Management, 17(1), 99-120. https://doi.org/10.1177/014920639101700108.

Brettel, M., \& Rottenberger, J. D. (2013). Examining The Link Between Entrepreneurial Orientation and Learning Processes in Small and Medium-Sized Enterprises. Journal of Small Business Management, 51(4), 471-490. https://doi.org/10.1111/jsbm.12002.

Campos, H. M., Nuno de la Parra, J. P., \& Parellada, F. S. (2012). The Entrepreneurial Orientation- Dominant Logic-Performance Relationship In New Ventures: An Exploratory Quantitative Study. Brazilian Administration Review, 9(Spe), 60-77.

Ciampi, F., Demi, S., Magrini, A., Marzi, G., \& Papa, A. (2020). Exploring The Impact Of Big Data Analytics Capabilities On Business Model Innovation: The Mediating Role of Entrepreneurial Orientation. Journal of Business Research, 123, 1-13. https://doi. org/10.1016/j.jbusres.2020.09.023.

D’Angeloa, A., \& Presutti, M. (2019). SMEs International Growth: The Moderating Role of Experience on Entrepreneurial and Learning Orientations. International Business Review, 28(3), 613-624.

Hair Jr., J. F., Black, W. C., Babin, B. J., \& Anderson, R. E. (2013). Multivariate Data Analysis: Global Perspective. New Jersey: Pearson Prentice Hall.

Hernández-Perlines, F. (2016). Entrepreneurial Orientation in Hotel Industry: Multi-Group Analysis of Quality Certification. Journal of Business Research, 69(10), 4714-4724. https://doi.org/10.1016/j.jbusres.2016.04.019.

Kiyabo, K., \& Isaga, N. (2020). Strategic Entrepreneurship, Competitive Advantage, And Smes' Performance In The Welding Industry In Tanzania. Journal of Global Entrepreneurship Research, 9, 62. https://doi.org/10.1186/s40497-019-0188-9.

Linares, R. H., Kellermanns, F. W., \& López-Fernández, M. C. (2018). A Note on The Relationships Between Learning, Market, and Entrepreneurial Orientations in Family and Nonfamily Firms. Journal of Family Business Strategy, 9(3), 192-204.

MacGregor, R. C. (2004). Factors Associated with Formal Networking in Regional Small Business: Some Findings From a Study of Swedish SMEs. Journal of Small Business and Enterprise Development, 11(1), 60-74. https://doi.org/10.1108/14626000410519100.

Mahmood, R., \& Hanafi, N. (2013). Entrepreneurial Orientation and Business Performance of Women-Owned Small and Medium Enterprises in Malaysia: Competitive Advantage as a Mediator. International Journal of Business and Social Science, 4(1), 82-90.

Martin, S. L., \& Javalgi, R. R. G. (2016). Entrepreneurial Orientation, Marketing Capabilities and Performance: The Moderating Role of Competitive Intensity on Latin American International New Ventures. Journal of Business Research, 69(6), 2040-2051. https:// doi.org/10.1016/j.jbusres.2015.10.149. 
Mc Cartan-Quinn, D., \& Carson, D. (2003). Issues Which Impact Upon Marketing in The Small Firm. Small Business Economics, 21(2), 201-213. https://doi.org/10.1023/A:1025070107609.

Muafi. (2014). Organizational Performance and Competitive Advantage Determinants of Creative SMEs. European Journal of Economics and Management, CXVI, 1-53.

Mustafa, M., \& Menon, J. (2015). Risk Factors,Diagnosis, and Management of Peptic ulcer Disease. IOSR Journal of Dental and Medical Sciences, 14(7), 2279-2861. https://doi. org/10.9790/0853-14784046.

Mustikowati, R. I., \& Tysari, I. (2015). Orientasi Kewirausahaan, Inovasi, Dan Strategi Bisnis Untuk Meningkatkan Kinerja Perusahaan (Studi Pada Ukm Sentra Kabupaten Malang). Jurnal Ekonomi Modernisasi, 10(1), 23-30. https://doi.org/10.21067/jem.v10i1.771.

Ramaswami, S. N., Srivastava, R \& Bhargava, M. (2006). Market-Based Assets and Capabilities, Business Processes, and Financial Performance. Journal of The Academy of Marketing Science, 37(2), 97-116.

Real, J. C., Roldán, J. L., \& Leal, A. (2014). From Entrepreneurial Orientation and Learning Orientation to Business Performance: Analysing The Mediating Role of Organizational Learning and The Moderating Effects of Organizational Size. British Journal of Management, 25(2), 186-208. https://doi.org/10.1111/j.1467-8551.2012.00848.x.

Rhee, J., Park, T., \& Lee, D. H. (2010). Drivers of Innovativeness and Performance for Innovative SMEs in South Korea: Mediation of Learning Orientation. Technovation, 30(1), 65-75. https://doi.org/10.1016/j.technovation.2009.04.008.

Ribeiro, M. A., Adam, I., Kimbu, A. N., Afenyo-Agbe, E., Adeola, O., Figueroa-Domecqa, C., \& de Jonge, A. (2021). Women Entrepreneurship Orientation, Networks and Firm Performance in The Tourism Industry in Resource-Scarce Contexts. Tourism Management, 86, 104343. https://doi.org/10.1016/j.tourman.2021.104343.

Saleh, A. S., \& Ndubisi, N. (2006). An evaluation of SME development in Malaysia. International Review of Business Research Paper, 2(1), 1-14.

Salleh, F., \& Ibrahim, M. D. (2013). The Relationship Between Risk-Taking Propensity and Demographic Characteristics Among MSEs in Malaysia. Journal for Global Business Advancement, 6(1), 38-49. https://doi.org/10.1504/JGBA.2013.053477.

Shepherd, D., \& Wiklund, J. (2009). Are We Comparing Apples With Oranges? Appropiateness of Knowledge Accumulation Across Growth Studies. Journal of Management, 33(1), 105-124. https://doi.org/10.1111/j.1540-6520.2008.00282.x.

Soares, G. G., Braga, V. L. S., Marques, C. S. E., \& Ratten, V. (2020). Corporate Entrepreneurship Education's impact on family business sustainability: A case study in Brazil. The International Journal of Management Education, 19(1), 100424. https://doi.org/10.1016/j. ijme.2020.100424.

Wang, C. L. (2008). Entrepreneurial Orientation, Learning Orientation, and Firm Performance. Entrepreneurship Theory And Practice, 32(4), .635-657. https://doi.org/10.1111/j.15406520.2008.00246.x.

Wijetunge, W. A. D. . (2016). Service Quality, Competitive Advantage and Business Performance in Service Providing SMEs in Sri Lanka. International Journal of Scientific and Research Publications, 6(7), 720-728. 
Wiklund, J. (1999). The Sustainability of the Entrepreneurial Orientation. Performance Relationship. Entrepreneurship Theory and Practice, 24(1), 37-48. https://doi. org/10.1177/104225879902400103.

Wiklund, Johan, \& Shepherd, D. (2005). Entrepreneurial Orientation and Small Business Performance: A Configurational Approach. Journal of Business Venturing, 20(1), 71-91. https://doi.org/10.1016/j.jbusvent.2004.01.001.

Zhao, Y., Li, Y., Lee, S. H., \& Chen, L. B. (2011). Entrepreneurial Orientation, Organizational Learning, and Performance: Evidence From China. Entrepreneurship: Theory and Practice, 35(2), 293-317. https://doi.org/10.1111/j.1540-6520.2009.00359.x.

Zhou, K. Z., Brown, J. R., \& Dev, C. S. (2009). Market Orientation, Competitive Advantage, and Performance: A Demand-Based Perspective. Journal of Business Research, 62(11), 1063-1070. https://doi.org/10.1016/j.jbusres.2008.10.001. 